\title{
The International Incidence of Traumatic Brain Injury: A Systematic Review and Meta-Analysis
}

\author{
Rita Nguyen, Kirsten M. Fiest, Jane McChesney, Churl-Su Kwon, Nathalie Jette, \\ Alexandra D. Frolkis, Callie Atta, Sarah Mah, Harinder Dhaliwal, Aylin Reid, \\ Tamara Pringsheim, Jonathan Dykeman, Clare Gallagher
}

\begin{abstract}
Background: Understanding the epidemiology of traumatic brain injury (TBI) is essential to shape public health policy, implement prevention strategies, and justify allocation of resources toward research, education, and rehabilitation in TBI. There is not, to our knowledge, a systematic review of population-based studies addressing the epidemiology of TBI that includes all subtypes. We performed a comprehensive systematic review and meta-analysis of the worldwide incidence of TBI. Methods: A search was conducted on May 23, 2014, in Medline and EMBASE according to Preferred Reporting Items for Systematic Reviews and Meta-Analyses guidelines. Abstracts were screened independently and in duplicate to identify original research. Study quality and ascertainment bias were assessed in duplicate using a previously published tool. Demographic data and incidence estimates from each study were recorded, along with stratification by age, gender, year of data collection, and severity. Results: The search strategy yielded 4944 citations. Two hundred and sixteen articles met criteria for full-text review; 144 were excluded. Hand searching resulted in ten additional articles. Eighty-two studies met all eligibility criteria. The pooled annual incidence proportion for all ages was 295 per 100,000 (95\% confidence interval: 274-317). The pooled incidence rate for all ages was 349 (95\% confidence interval: 96.2-1266) per 100,000 person-years. Incidence proportion and incidence rate were examined to see if associated with age, sex, country, or severity. Conclusions: We conclude that most TBIs are mild and most TBIs occur in males among the adult population. The incidence of TBI varies widely by ages and between countries. Despite being an important medical, economic, and social problem, the global epidemiology of TBI is still not well-characterized in the current literature. Understanding the incidence of TBI, particularly mild TBI, remains challenging because of nonstandardized reporting among neuroepidemiological studies.
\end{abstract}

RÉSUMÉ: Revue systématique et méta-analyse de l'incidence internationale des traumatismes cranio-cérébraux. Contexte: Mieux comprendre l'épidémiologie des traumatismes cranio-cérébraux (TCC) demeure indispensable si l'on veut façonner des politiques de santé publique, mettre en œuvre des stratégies de prévention et justifier l'affectation de ressources consacrées à la recherche, à l'éducation et à la réadaptation en matière de TCC. À notre connaissance, il n'existe pas de revue systématique des études populationnelles qui tiendrait compte de l'épidémiologie des TCC et de tous leurs soustypes. Voilà pourquoi nous avons mené une telle revue de façon détaillée en plus de procéder à une méta-analyse de l'incidence internationale des TCC. Méthodes: C'est au moyen de MEDLINE et d'Embase ${ }^{\circledR}$ que nous avons, le 23 mai 2014, effectué notre recherche. Pour ce faire, nous nous en sommes tenus aux lignes directrices de l'outil PRISMA (Preferred Reporting Items for Systematic Reviews and Meta-Analyses). Des résumés reproduits en deux exemplaires ont ainsi été passés au crible de façon séparée afin de repérer l'étude d'origine. Nous avons aussi évalué la qualité des études et leurs biais d'échantillonnage au moyen d'un outil publié précédemment. Pour chaque étude, nous avons consigné leurs données démographiques, leurs estimations en matière d'incidence mais aussi la stratification selon l'âge et le sexe, l'année de collecte des données et la sévérité des TCC. Résultats: Notre stratégie de recherche nous a permis de repérer 4944 citations. De plus, 216 articles ont satisfait aux critères d'une revue complète tandis que 144 ont été éliminés en fonction de ces mêmes critères. Au moyen d'une recherche manuelle, nous avons aussi pu obtenir 10 articles additionnels. Au total, 82 études ont rempli tous les critères d'admissibilité établis. L'incidence annuelle cumulée pour tous les groupes d'âge était de 295 sur 100000 (IC à 95\% : 274-317). Le taux d'incidence cumulée pour tous les groupes d'âge était de 349 (IC à 95\% : 96,2-1266) par 100000 personnes-années. Enfin, nous avons examiné l'incidence cumulée et le taux d'incidence afin de vérifier dans quelle mesure ils étaient associés aux variables suivantes : âge, sexe, pays d'origine ou sévérité d'un TCC. Conclusions: Nous sommes parvenus à la conclusion que la plupart des TCC sont mineurs et que leur incidence, au sein de la population adulte, est plus élevée chez les hommes. À noter que l'incidence des TCC varie grandement selon les âges ou d'un pays à l'autre. Bien que l'épidémiologie mondiale des TCC constitue un enjeu majeur sur les plans médical, économique et social, elle demeure plutôt méconnue dans les ouvrages scientifiques actuels. Mieux comprendre l'incidence des TCC, notamment ceux qui sont mineurs, demeure un défi en raison des aspects non standardisés de la divulgation scientifique propre aux études neuro-épidémiologiques.

From the Department of Clinical Neurosciences (RN, KMF, NJ, CA, SM, HD, TP, CG), University of Calgary, Calgary, Alberta, Canada; Department of Community Health Sciences \& O'Brien Institute for Public Health (KMF, JM, NJ, ADF, TP, JD), University of Calgary, Calgary, Alberta, Canada; Hotchkiss Brain Institute (NJ, CG), University of Calgary, Calgary, Alberta, Canada; Department of Neurosurgery (C-SK), King's College Hospital, Denmark Hill, London, UK; Department of Neurology (AR), University of California Los Angeles,

Los Angeles, California.

Received August 19, 2015. Final Revisions Submitted February 17, 2016. Date of Acceptance March 14, 2016.

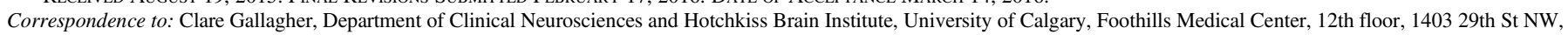
Calgary, Alberta, Canada T2N 2T9. E-mail: galclare@gmail.com. 
Keywords: Traumatic Brain Injury, Head Trauma, Epidemiology, Incidence, Systematic Review

doi:10.1017/cjn.2016.290

Can J Neurol Sci. 2016; 43: 774-785

Traumatic brain injury (TBI) is the leading cause of death and disability in people younger than age 45 in the United States. ${ }^{1}$ Falls and motor vehicle accidents are the leading causes of TBI. ${ }^{2}$ According to the Centers for Disease Control and Prevention, 1.7 million TBIs occur annually in the United States and TBI is associated with $30.5 \%$ of all injury-related deaths. In 2010, the economic burden of TBI in the United States, which includes direct medical and indirect costs such as loss of productivity, was estimated to be $\$ 76.5$ billion. $^{3}$

The Glasgow Coma Scale (GCS) is the most widely used clinical scoring system in the assessment of TBI severity. Persons with a GCS score of 3 through 8 are classified as having a severe TBI, 9 through 12 as moderate TBI, and 13 through 15 as mild TBI. Although mild TBIs or concussions represent $75 \%$ of annual TBIs in the United States, the costs related to severe TBI hospitalizations account for approximately $90 \%$ of the TBIrelated cost. However, mild concussions (including those not seen in an inpatient hospital setting) can also be associated with significant ongoing costs in terms of disability, lost work, or neuropsychiatric complications. ${ }^{4,5}$ In addition, $43 \%$ of patients that require hospitalization continue to have cognitive, social, or physical deficits 1 year postinjury. .,6 $^{3,6}$

Thus the immediate and long-term consequences of all ranges of TBI create significant economic and societal burden. Understanding the epidemiology of TBI is essential to shape public health policy, implement prevention strategies, and justify allocation of resources toward research, education, and rehabilitation in TBI. Current scientific literature contains wide variations in the incidence of TBI. Although there have been reviews on the epidemiology of TBI, most are not systematic, ${ }^{7,8}$ focus only on one TBI type (e.g. mild TBI), ${ }^{9}$ or are very specific to one population (e.g. homeless people, ${ }^{10}$ incarcerated individuals ${ }^{11}$ ).

Furthermore, a recent meta-analysis of 15 studies on the prevalence of TBI in the adult general population ${ }^{5}$ reported that $12 \%$ of adults in developed countries had a history of TBI. Definitions of TBI remain imprecise in the literature, and this persisting problem has led to wide epidemiological estimates that vary according to study design and data source. There has not been, to our knowledge, a systematic review of population-based studies addressing the international incidence of TBI that includes all subtypes. The goal of our study was to carry out a comprehensive and international systematic review and meta-analysis of the incidence of TBI and examine factors associated with estimate heterogeneity.

\section{METHODS}

The systematic review and meta-analysis were conducted according to a predetermined protocol and established guidelines (Preferred Reporting Items for Systematic Reviews and MetaAnalyses). ${ }^{12}$ The search strategy (Supplementary Appendix 1) was developed by study authors with expertise in TBI and/or epidemiology and in consultation with a research librarian with extensive systematic review expertise. The search was conducted on May 23, 2014, in the Medline and EMBASE databases using key words and topic headings related to TBI and concussion. References were exported and managed using EndNote X5. ${ }^{13}$ All studies reporting data from 1985 onwards were eligible for inclusion in this review to identify studies after the introduction of magnetic resonance imaging in clinical practice. Articles were included if published in English or French; translation in other languages was not available for this study. Review articles on the epidemiology of TBI and the reference lists of included articles were also hand searched for additional articles.

Abstracts and titles of all references were screened independently, in duplicate, to identify original research that reported on the incidence of TBI. Abstracts that were clearly not populationbased were excluded at this stage. Two reviewers independently screened the full-text articles of abstracts identified in the first phase. Articles were included if they met the following criteria: (1) original research, (2) population-based (sampling all members of a defined population or using probability-based sampling to select the population), and (3 reported an epidemiology estimate (e.g. prevalence, incidence, data needed to calculate an incidence estimate) of TBI. Prevalence papers were also identified to ensure an incidence estimate was not reported in it. Disagreements pertaining to the inclusion of articles were resolved by consensus and involvement of a third party as necessary.

Two reviewers extracted and reached agreement on data from included articles using a standard data collection form. When multiple articles reporting data from the same study population were encountered, the most comprehensive data was used. For example, numerous articles may report on data from the same registry. In cases where the articles reported on different data collection years or subgroups (sex, age), all data (every article) were included. Demographic data such as age, sex, and study location were recorded. Diagnostic data were collected, as were the sources of these data and definitions/diagnostic criteria for TBI. Incidence estimate(s) of TBI from each study were recorded, along with any stratification by age, gender, year of data collection, or TBI severity.

Incidence estimates were separated into two distinct groups: incidence proportion and incidence rate. The incidence rate of TBI is the number of new cases of TBI over the total amount of persontime at risk for having a TBI during a specified period. The incidence proportion is the number of new cases of TBI over the total number of people in the population at risk for having a TBI during a specified period. These distinct categories may account for different periods at risk and therefore were not combined in the current study.

Incidence estimates were stratified by the following variables: age, sex, continent, and TBI severity. Age was categorized as pediatric $(<15$ years of age), elderly ( $>65$ years of age), or all ages. TBI severity was grouped into three mutually exclusive groups where available: mild, moderate, and severe. All analyses included persons of all TBI severities and ages (except when stratified based on these variables). Quality of the included studies was evaluated independently by two reviewers using an assessment tool (Supplementary Appendix 2) that was developed based on a previous study quality scoring system and published guidelines on assessing ascertainment bias in observational studies. ${ }^{14,15}$ 
The quality tool assessed sample representativeness, condition assessment, and statistical methods. Each study was given a quality score of 0 to 8 based on fulfillment of the quality criteria.

To assess for significant between-study heterogeneity, the Cochrane Q statistic was calculated and $I^{2}$ was used to quantify the magnitude of between-study heterogeneity. When statistically significant heterogeneity ( $Q$ statistic $\mathrm{p}$ value $<0.05$ ) was absent, the pooled estimate and $95 \%$ confidence intervals (CIs) were calculated using a fixed-effect model. When significant heterogeneity was present, a random-effects model was used. Publication bias was investigated visually using funnel plots and statistically using Begg's and Egger's tests.

For all tests, $\mathrm{p}<.05$ was deemed to be significant. All statistical analyses were carried out in $\mathrm{R}$, version 2.14 ( $\mathrm{R}$ Development Core Team). The metafor package was used to produce the pooled estimates, forest plots, and publication bias assessment. ${ }^{16-18}$ The metafor package was used to conduct meta-regressions by age, sex, and so on using restricted maximum likelihood estimation. ${ }^{19}$

\section{Results}

The results of the search strategy yielded a total of 4944 citations: 2,516 from Medline and 2,428 from EMBASE (Figure 1). After the initial screen, 216 articles met the criteria for full-text review, of which 144 were excluded ( 38 were not population-based, 39 did not report an incidence estimate of TBI, 18 were not original data, 17 were only abstracts, 13 reported data before 1985, eight did not focus on TBI, seven reported on sports-related injuries, and four reported on duplicate data sources). Hand searching resulted in the inclusion of ten additional articles. From the 82 eligible studies

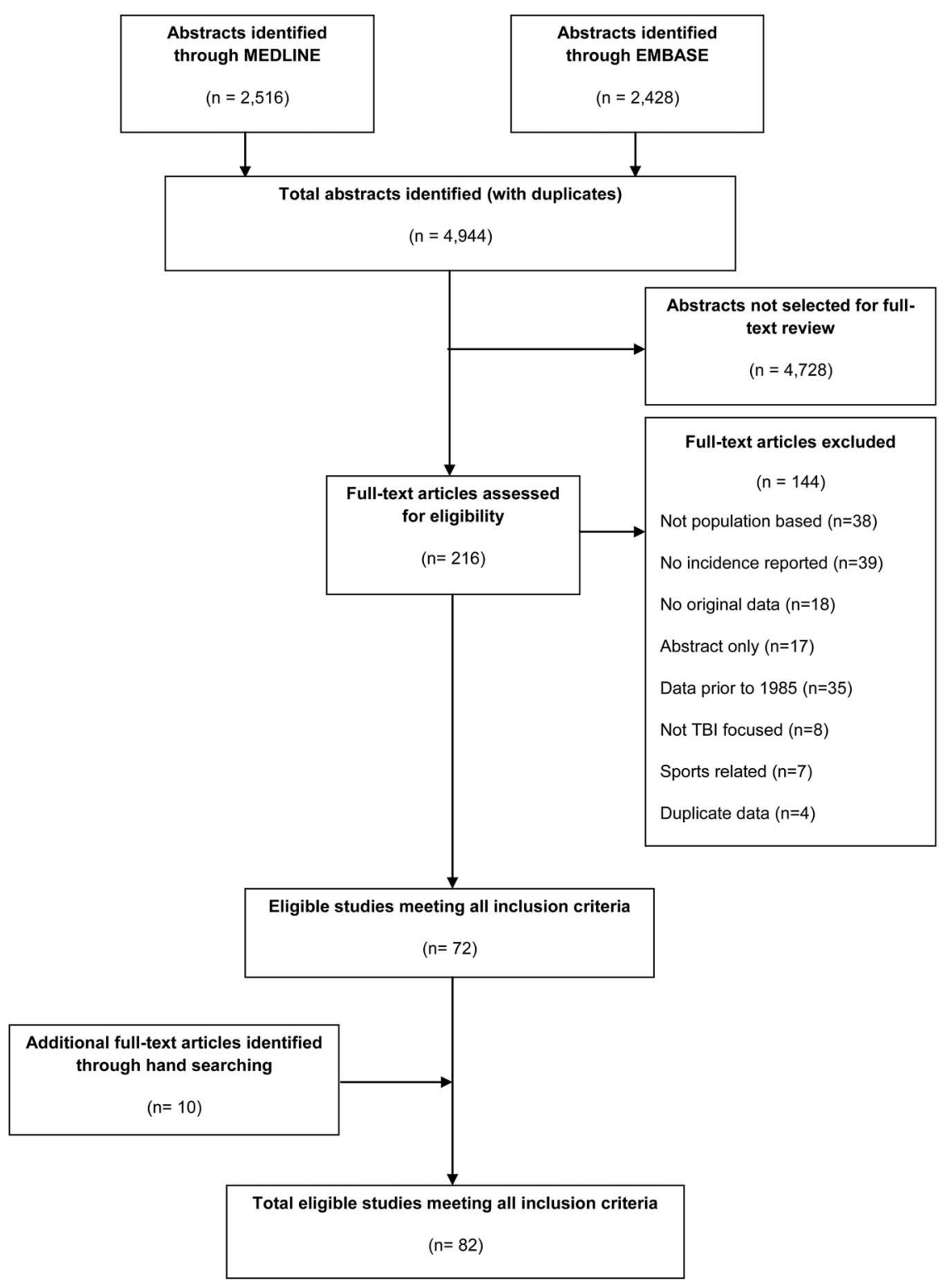

Figure 1: Flow chart of search strategy for traumatic brain injury (TBI). 4944 citations were originally identified. 216 full-text articles were assessed for eligibility. 10 studies were identified through hand searching; ultimately 82 studies were included in the systematic review. 
overall (original search and hand searching), 77 were included in the meta-analysis. Characteristics of the 82 included studies are shown in Supplementary Table 3A-D.

All of the included studies reported on the incidence of TBI. Thirty-nine of the studies reported on data from North America, 32 from Europe, six from Australia, three from Asia, one from Africa, two from New Zealand, and one from South America (some studies reported data from more than one country).

Probability-based sampling was used in 18 studies, ${ }^{20-36}$ whereas the remainder of the included studies sampled the entire target population area. For example, Koepsell and colleagues ${ }^{32}$ used a two-stage stratified sampling design to: (1) select hospital emergency departments and (2) select children with TBI presenting to the emergency room, though not admitted. In contrast, Engberg and colleagues ${ }^{37}$ used the Danish National Hospital register as their sampling frame, which covers more than $99 \%$ of all discharges in Denmark.

\section{Incidence of Traumatic Brain Injury}

Sixty-three studies ${ }^{20-31,35-89}$ met all eligibility criteria for the incidence proportion of TBI, of which 39 met eligibility criteria for inclusion in the meta-analysis. Studies could only be included in the meta-analysis if they provided an incidence estimate with CIs or data required to calculate the CI. The pooled annual incidence proportion for pediatric $(<15$ years of age) populations using a random-effects model was 110 per 100,000 (95\% CI: 34-358) (Figure 2). Significant heterogeneity existed between estimates, $I^{2}=100 \%$, Q p value $<0.0001$. In elderly ( $>65$ years of age) populations, the pooled annual incidence proportion was 166 per 100,000 (95\% CI: 143-194). Significant heterogeneity existed between estimates, $I^{2}=100 \%, \mathrm{Q}$ value $<0.0001$. For those studies reporting on all age groups, the pooled annual incidence proportion was 295 (95\% CI: 274-317).Significant heterogeneity existed between estimates, $I^{2}=100 \%, \mathrm{Q}$ p value $<0.0001$. The estimates ranged from 69 per 100,000 in a North American study of all ages ${ }^{59}$ to 1750 per 100,000 in a New Zealand study of all ages. ${ }^{66}$

Twenty studies $24,32,33,35,39,41,54,90-102$ met all eligibility criteria for the incidence rate of TBI, and 14 were eligible for inclusion in the meta-analysis (Figure 3). In all age groups, the pooled annual incidence rate was 349 per 100,000 person-years (95\% CI: $96-$ 1266), with significant heterogeneity between studies, $I^{2}=100 \%$, $\mathrm{Q}$ p value $<0.0001$. The pooled annual incidence rate in pediatric populations was 134 per 100,000 person-years $(95 \%$ CI: 105-171), with significant heterogeneity between estimates, $I^{2}=100 \%$, Q p value $<0.0001$. A random-effects model found the overall pooled annual incidence rate of TBI in adolescents, adults, and elderly to be 319 (95\% CI: 313-326) per 100,000 person-years. No statistical heterogeneity existed between the estimates, $I^{2}=0 \%$, Q p value 0.384 . For those studies combining adolescents and adults, the pooled annual incidence rate was 618 per 100,000 person-years (95\% CI: 603-634), with significant heterogeneity present, $I^{2}=94.3 \%$, Q p value $<0.0001$.

\section{Sources of Heterogeneity}

\section{Age}

For the incidence proportion of TBI, estimates were significantly higher in studies of all ages compared with elderly only ( $>65$ years of age) studies. There were no significant differences between pediatric ( $<18$ years of age) and elderly studies, nor pediatric and all ages studies.

Significant differences existed among all age groups in the incidence rate of TBI (Figure 3). The incidence rate for combined adolescent and adult studies was significantly higher than that of pediatric populations and combined adult, adolescent, and elderly populations. The incidence rate of TBI in pediatric studies was significantly lower than that of combined adolescent, adult, and elderly studies and that of combined adolescent and adult studies.

\section{Sex}

The incidence proportion of TBI in males was significantly greater than that of females. The pooled annual incidence proportion using a random effects model for females was 86 per 100,000 (95\% CI: 71-105) and 151 per 100,000 (95\% CI: $126-$ 181) for males. Differences in incidence rate estimates of TBI between males and females did not reach statistical significance. The pooled annual incidence rate using a random-effects model for TBI in females was 195 per 100,000 person-years (95\% CI: $84-452)$ and in males was 388 per 100,000 person-years (95\% CI: 138-1092). Included studies did not provide sufficient information for us to be able to analyze sex differences stratified by age groups.

\section{Continent}

Meta-analysis by continent was available for both incidence proportion and rate of TBI (Figure 4) There was no significant difference in the pooled annual incidence proportion of TBI between European (228 per 100,000 [95\% CI: 158-329]) and North American studies (331 per 100,000 [95\% CI: 305-359]). One New Zealand study reported the highest incident proportion (1750 per 100,000 [95\% CI: 1111-2755]); when combined with Australia, this gave the Australasian region an incidence proportion of 415 per 100,000 (95\% CI: 25-6853). In incidence rate studies reporting on all age groups, there was no significant difference in the incidence rate of TBI between continents. The European rate was 147 per 100,000 person-years (pooled data, 95\% CI: 33-649), the North American rate 632 per 100,000 person years (pooled data, 95\% CI: 511-781), and the rate in one study from New Zealand 790 per 100,000 person-years (95\% CI: 750-833).

\section{Severity}

Information on disease severity was available for both the incidence proportion and rate of TBI. There was a significant difference between all severity levels in the incidence proportion according to meta-regression analyses $(p<0.05)$. The pooled annual incidence proportion of mild TBI was 224 per 100,000 (95\% CI: 120-418), moderate TBI was 23 per 100,000 (95\% CI: 18-29), and severe TBI was 13 per 100,000 (95\% CI: 10-18).

There was also a significant difference between severity levels in the incidence rate of TBI according to meta-regression analyses $(\mathrm{p}<0.05)$. The pooled annual incidence rate of mild TBI was highest, at 982 per 100,000 person-years (95\% CI: 756-1276), followed by moderate and severe TBI at 41 per 100,000 personyears, and severe TBI at 6 per 100,000 person-years (95\% CI: 3-12). 
THE CANADIAN JOURNAL OF NEUROLOGICAL SCIENCES

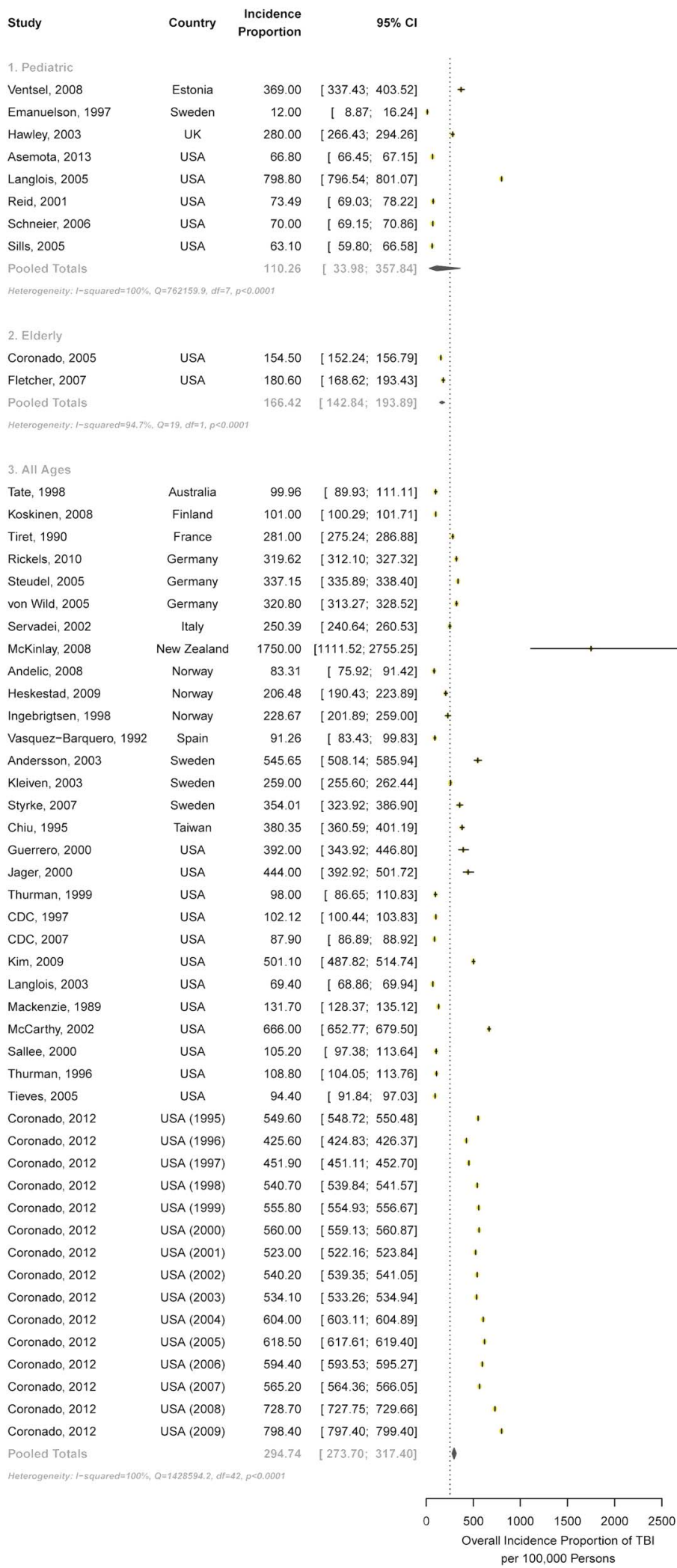

Figure 2: Incidence proportion of TBI, across age groups. Forest plot comparison of TBI incidence proportion by age subgroup. The horizontal bars depict corresponding 95\% confidence intervals for each estimate. The incidence proportion of TBI in pediatric populations (110.26, CI: 33.98357.84), elderly populations (166.42, CI: 142.84-193.89), and all ages (294.74, CI: 273.70-317.40) is shown. 


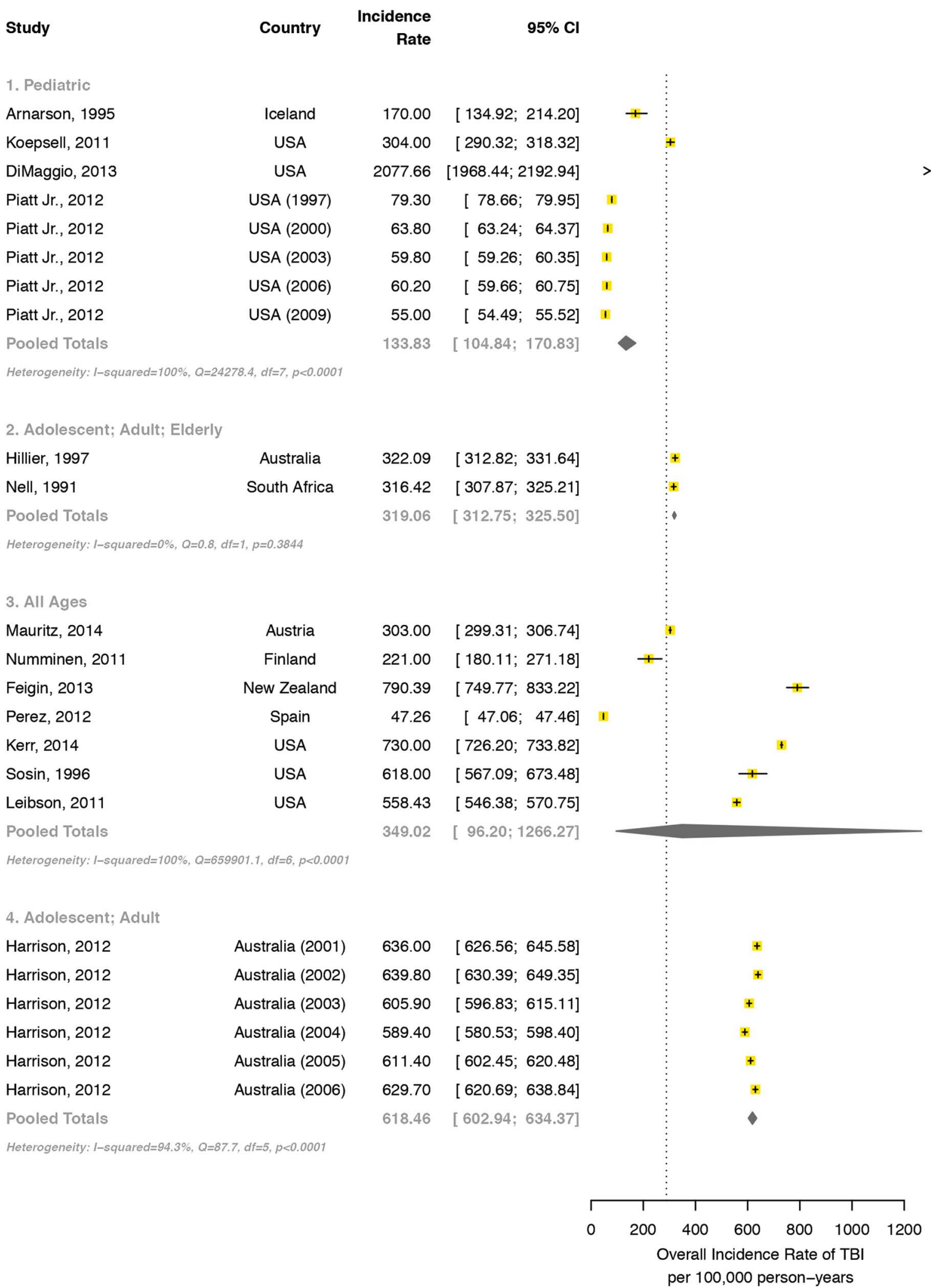

Figure 3: Incidence rate of TBI, across age groups. Forest plot comparison of TBI incidence rate by age subgroup. The horizontal bars depict corresponding 95\% confidence intervals for each estimate. The incidence rate for combined adolescent and adult studies was significantly higher than that of pediatric populations and combined adult, adolescent, and elderly populations. 
THE CANADIAN JOURNAL OF NEUROLOGICAL SCIENCES

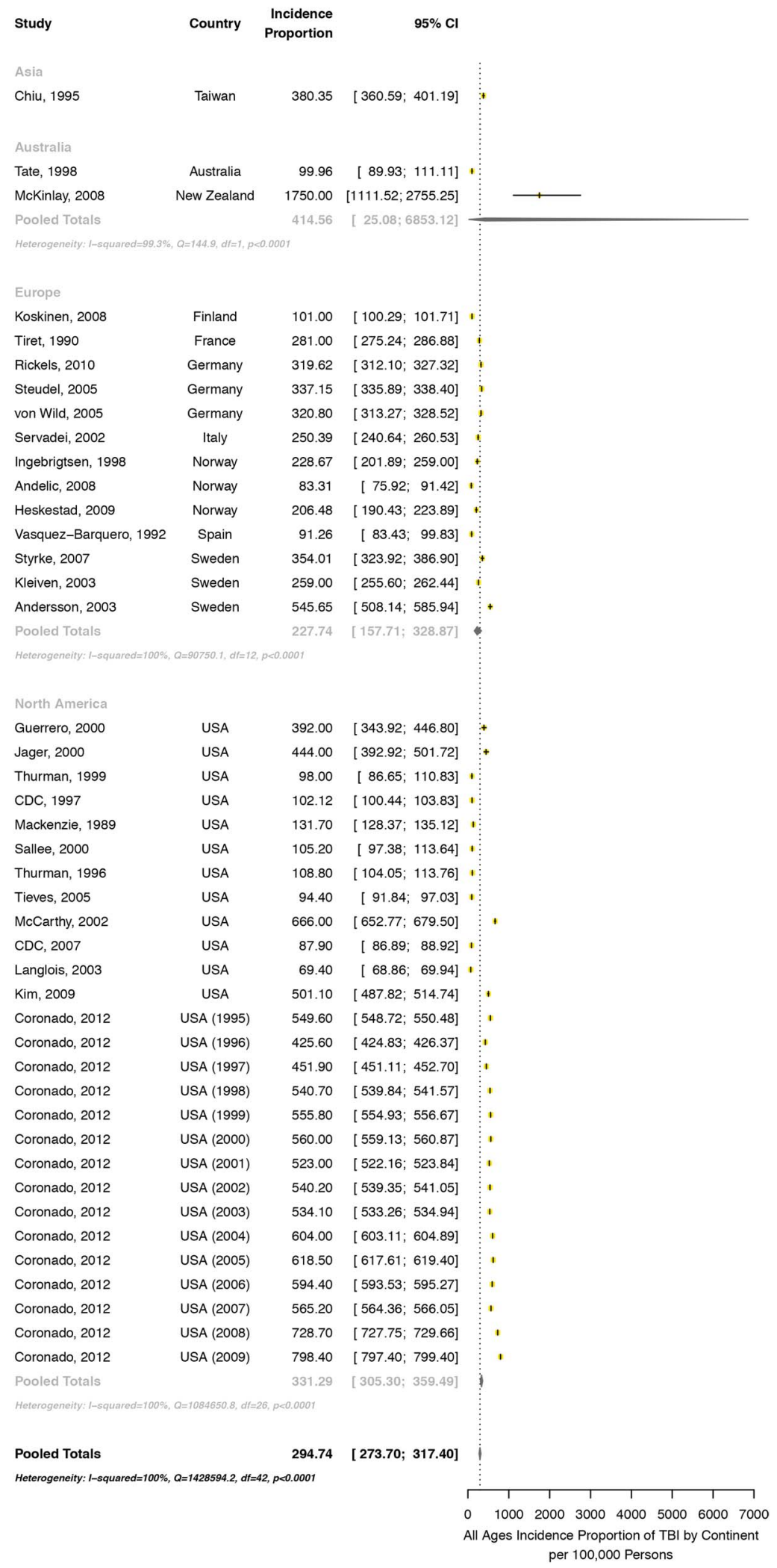

Figure 4: Incidence proportion of TBI, across continents. Forest plot comparison of TBI incidence proportion by continent subgroup. The horizontal bars depict corresponding $95 \%$ confidence intervals for each estimate. The incidence proportion of TBI was lower in Europe (227.74, CI: 157.71-328.87) than North America (331.29, CI: 305.30-359.49), Asia (380.35, CI: 360.59-401.19) or Australasia (414.56, CI: 25.08-6853.12). 


\section{Publication Bias}

For the incidence proportion of TBI, significant funnel plot asymmetry was found for Begg's $(\mathrm{p}=0.0037)$, but not Egger's test $(\mathrm{p}>0.05)$. Upon visual inspection, the funnel plot appeared symmetrical. There was an insufficient sample size to calculate publication bias for the incidence rate and period prevalence of TBI.

\section{Study Quality}

The median study quality score for studies necessitating a response rate was $6 / 8$ (range $4-7, n=69$ ). For those not necessitating a response rate, the median study quality score was $6 / 6$ (range 4-6, n=13). Eighty studies described the target population in detail and all sampled either the entire population or used probability sampling (Supplementary Table 4A,B). Sixty-four studies reported a response rate greater than $70 \%$, and 65 articles adequately described the nonresponders. Almost all studies reported a sample that was representative of the target population (72/82). All studies used standardized data collection methods; however, only 17 reported using diagnostic criteria to assess for the presence of TBI. The majority of the studies (54) did not report estimates with their accompanying confidence intervals or by subgroups.

\section{DISCUSSION}

TBI is an important cause of preventable morbidity and mortality worldwide. The economic and social impact of TBI is substantial because of both direct medical and rehabilitation costs and intangible costs resulting from disability and loss of productivity. ${ }^{88}$ Many cases of TBI are either unrecognized by health care professionals or unreported by the patient, and TBI has thus been termed a "silent epidemic" as many cases of TBI are not captured in epidemiological statistics. ${ }^{103}$ To implement effective preventive and treatment strategies for TBI, accurate information regarding the frequency of this condition in the general population is essential. We conducted a systematic review of the incidence of TBI with meta-analyses to estimate the incidence of this critical health problem globally and in important population subgroups.

There have been a number of literature reviews examining the incidence of TBI; however, these studies are not systematic, 6,7 provide information on only one subtype of TBI patients (i.e. those with mild ${ }^{9}$ or severe $\mathrm{TBI}^{101}$ ), a specific population (i.e. age groups ${ }^{104}$, incarcerated individuals), or focus on one geographic region. ${ }^{50}$ To the best of our knowledge, this is the first systematic review and meta-analysis that includes studies from around the world in all subgroups of TBI in all age groups. The results obtained provide valuable insight on the differences in TBI incidence worldwide, as well as factors that contribute to the heterogeneity of TBI incidence, which are important considerations when developing future studies examining TBI epidemiology.

In examining the method of data abstraction between the individual studies (Supplementary Table 3), diagnosis of TBI in a New Zealand study ${ }^{66}$ consisted of self-reported diagnosis via telephone interviews in addition to medical chart review, which may have resulted in a higher estimate that could be closer to the truth, although misclassification bias cannot be ruled out; conversely, a Finland study ${ }^{39}$ obtained diagnoses via hospital administrative health databases and International Classification of Diseases (ICD) codes. As such, patients with minor TBI that may not present to hospital for treatment are not captured in the Finnish study.

The incidence rate of the pediatric population is 134 per 100,000 person-years, compared with a pooled annual incidence rate in all ages of 349 per 100,000 person-years. These numbers are significantly lower compared with the incidence rate of adolescent and adult populations (618 per 100, 000) in one Australian study. ${ }^{98}$ Pooled analyses of the incidence proportion of TBI show an estimate in the pediatric population of 110 per 100,000 persons, in the elderly of 166 per 100,000 persons, and an overall proportion estimate in all ages of 295 per 100,000 persons. From these estimates of incidence rate and proportion, it is reasonable to infer that age contributes to heterogeneity and the majority of TBI occur in the adult population compared with either pediatric or elderly populations.

Further sources of heterogeneity were identified in the subgroups of sex and severity, with a higher proportion of males sustaining head injury and the majority of TBI being classified as mild. These trends are likely attributable to the propensity for young adult males to be involved in risk-taking behavior, ${ }^{105}$ with a resultant increased risk for head injury.

In looking at continental differences, pooled estimates were only available for incidence proportion of Europe and North America with single-study estimates for Asia, Australia, and New Zealand. The lowest incidence proportion was reported in Australia, ${ }^{79}$ followed by Europe, North America, and Asia. ${ }^{46}$ The highest incidence proportion was reported from a study in New Zealand. ${ }^{66}$ All studies included in the analysis obtained diagnoses of TBI via hospital records except for the study from New Zealand, ${ }^{66}$ which included telephone surveys and selfreports as well as evidence of visits to a general practitioner with a primary complaint of head injury, therefore possibly capturing incidences of minor TBI that do not present to hospital. This undoubtedly contributes to the significantly higher incidence proportion estimates for that region. In studies that reported incidence rate across all age groups, the lowest incidence rate was reported in Europe, followed by North America and New Zealand. Several theories can be postulated from the continental differences in incidence rate and proportion of TBI. Public awareness, driven in part by professional sporting organizations such as the National Football League, has led to the development of legislation in 42 states and the District of Columbia surrounding TBI in sports. ${ }^{106,107}$ The resulting cognizance, education, and regulation have led to increased prevention and safety measures, thereby contributing to the lower incidence proportion observed in North American studies. Furthermore, improved traffic and safety regulations have contributed to a decline in motor vehicle accidentrelated TBI injuries in high-income countries such as Europe and North America. ${ }^{108}$ Only single studies are available for incidence proportion and rate in Asia, Australia, and New Zealand. These studies may not represent the true incidence of head injury in this population; thus, additional epidemiological studies of head injury in these regions are necessary to draw reliable conclusions. A possible limitation of our study is that we did not include articles written in languages other than English or French; however, given the large number of studies we were able to include, we do not anticipate this to significantly alter the pooled annual incidence estimates.

The most significant limitation of our study lies in the considerable heterogeneity among studies. Several factors contribute 
to the heterogeneity in the analysis: (1) variations in methods of data collection and differences in identification of cases among studies; (2) underreporting of cases of TBI; and (3) inconsistencies in diagnostic definitions of TBI. Many studies included in our analysis identified cases of TBI through hospital and administrative datasets using coding classifiers such as the ICD-9. The ICD-9 is more pathologically based compared with the clinically oriented ICD-10. ${ }^{109}$ Thus TBI without overt pathologic features would not be captured. As such, identification of mild TBI using ICD-9 codifiers results in high false-negative results, ${ }^{110}$ although the system still has reasonable sensitivity and specificity for the identification of severe TBI. ${ }^{111}$ In addition, ICD codes are developed primarily for administrative purposes, and thus their use in epidemiological studies is convenient, but not ideal. Many of the studies only identified cases of TBI presenting to hospital. The majority of patients mild head injuries do not present to hospital, and those with severe injuries that die before presentation are not registered. This results in gross underestimation of the number of head injuries that do not present to medical professionals.

Perhaps the largest source of heterogeneity lies in the lack of a universal system for diagnosis and classification of TBI. Many studies use alterations in GCS scale as a means to diagnose TBI; however, not all TBIs present with changes in GCS. This specifically complicates the identification of mild TBI and studies in which telephone surveys and questionnaires were used. Language surrounding the definition of mild TBI is ambiguous, and physicians and laypeople use the terms head injury, brain injury, and concussion interchangeably without awareness of a discrete definition. In fact, there are approximately 41 systems described for the diagnosis and classification of mild TBI. ${ }^{112}$ Moreover, many health care authority bodies have independently published definitions for mild TBI. For example, The American Congress of Rehabilitation Medicine defines mild TBI as an injury resulting from "traumatically induced physiological disruption of brain function," 113 whereas the World Health Organization describes mild TBI as "an acute brain injury resulting from mechanical energy to the head from external forces." "114 The American Congress of Rehabilitation Medicine definition restricts mechanism of injury only to indirect trauma to the head, and the World Health Organization definition excludes any injuries involving drugs, alcohol, medications, or addition of other systemic injuries. Thus, it is apparent that both definitions restrict cases of TBI to a limited number of mechanisms and that the spectrum of TBI cases is captured in neither definition. The Working Group on Demographics and Clinical Assessment of the International Interagency Initiative toward Common Data Elements for Research in TBI and Psychological Health states a broader definition of TBI, stating that it is "an alteration in brain function or other evidence of brain pathology caused by an external force." 115 Despite this, vague terms such as "alteration in brain function" complicate the identification of cases, because confounders such as pain and medications can certainly cause alterations in brain function with or without brain injury. The use of diagnostic imaging studies for the identification of TBI is also problematic because commonly used techniques such as computed tomography scan overlook mild injuries. Thus, until an internationally accepted definition of TBI is developed, coupled with a universal diagnostic algorithm, epidemiological studies of TBI will be fraught with discrepancies.

\section{CONCLUSION}

In summary, we conclude that mild TBI is more common than moderate or severe TBI, and that the incidence of TBI is higher in males and lower at the extremes of age (i.e. pediatric or elderly). Furthermore, the incidence of brain injury seems to vary widely across countries but cross-country comparisons are difficult because of the significant heterogeneity between studies and the small number of studies that could be meta-analyzed. Despite being an important medical, economic, and social problem, the epidemiology of brain injury is not well-characterized in the current literature, and capturing the incidence of brain injury remains a challenge, particularly with mild TBI. Future areas of research should focus on standardizing epidemiological studies, reporting measures, and diagnostic criteria in brain injury. For example, future epidemiologic studies in TBI could focus on methods such as door-to-door studies or surveys, which have the advantage of capturing cases of brain injury that do not present to hospital. Thus, we presume that the true incidence of brain injury is likely greater than what is currently reported. Continued research into the epidemiology of this disease is necessary in order to inform evidence-based health care, prevention, treatment, and rehabilitation initiatives.

\section{ACKNOWLEDGMENTS AND FUNDING}

This study is part of the National Population Health Study of Neurological Conditions. We wish to acknowledge the membership of Neurological Health Charities Canada and the Public Health Agency of Canada for their contribution to the success of this initiative.

Funding for the study was provided by the Public Health Agency of Canada. The opinions expressed in this publication are those of the authors/researchers, and do not necessarily reflect the official views of the Public Health Agency of Canada.

\section{Disclosures}

NJ has served as a principal investigator and received a shared research grant from Hotchkiss Brain Institute and Pfizer; served as a principal investigator for Canada Research Chair Program and Alberta Innovates Health Solutions; holds a Canada Research Chair Tier 2 in Neurological Health Services Research and held an Alberta Innovates Health Solutions Population Investigator Award during part of this study; salary support from a government agency and a provincial health research funding agency has been paid to NJ's university. ADF has received an AIHS research studentship. KMF received an AIHS research studentship. The remaining authors have nothing to disclose.

\section{SuPPlementary Materials}

For supplementary material/s referred to in this article, please visit http://dx.doi.org/doi:10.1017/cjn.2016.290

\section{REFERENCES}

1. Brain Trauma Foundation. Traumatic Brain Injury Statistics. Brain Trauma Foundation; 2013. https://www.braintrauma.org/

2. Faul M, Xu L, Wald MM, Coronado VG. Traumatic Brain Injury in the United States: Emergency Department Visits, Hospitalizations and Deaths 2002-2006. Atlanta (GA): Centers for Disease Control and Prevention, National Center for Injury Prevention 
and Control; 2010. https://www.cdc.gov/traumaticbraininjury/ pdf/blue_book.pdf

3. Finkelstein $\bar{E}$, Corso P, MIller T. The incidence and economic burden of injuries in the United States. New York: Oxford University Press; 2006.

4. Thurman DJ. The epidemiology of traumatic brain injury in children and youths: a review of research since 1990. J Child Neurol. 2016;21:20-7.

5. DeKosky ST, Blennow K, Ikonomovic MD, Gandy S. Acute and chronic traumatic encephalopathies: pathogenesis and biomarkers. Nat Rev Neuro. 2013;9:192-200.

6. Selassie AW, Zaloshnja E, Langlois JA, Miller T, Jones P, Steiner C. Incidence of long-term disability following traumatic brain injury hospitalization, United States, 2003. J Head Trauma Rehabil. 2008;23:123-31.

7. Bruns J, Jr., Hauser WA. The epidemiology of traumatic brain injury: a review. Epilepsia. 2003;44(Suppl 10):2-10.

8. Corrigan JD, Selassie AW, Orman JA. The epidemiology of traumatic brain injury. J Head Trauma Rehabil.J 2010;25: 72-80.

9. Cassidy JD, Carroll LJ, Peloso PM, Borg J, von Holst H, Holm L, et al. Incidence, risk factors and prevention of mild traumatic brain injury: results of the WHO Collaborating Centre Task Force on Mild Traumatic Brain Injury. J Rehabil Medi. 2004(43 Suppl):28-60.

10. Topolovec-Vranic J, Ennis N, Colantonio A, Cusimano MD, Hwang SW, Kontos P, et al. Traumatic brain injury among people who are homeless: a systematic review. BMC Public Health. 2012;12:1059.

11. Farrer TJ, Hedges DW. Prevalence of traumatic brain injury in incarcerated groups compared to the general population: a metaanalysis. Prog NeuropsychopharmacolBiological Psychiatry. 2011;35:390-4.

12. Moher D, Liberati A, Tetzlaff J, Altman D, Group P. Preferred reporting items for systematic reviews and meta-analyses: the PRISMA Statement. PLoS Med. 2009;6(7). PMID: 19621072.

13. Endnote X5 software. Thompson Reuters; 2011.

14. Boyle MH. Guidelines for evaluating prevalence studies. Evidence Based Mental Health. 1998;1:37-9. doi:10.1136/ebmh.1.2.37.

15. Loney PL, Chambers LW, Bennett KJ, Roberts JG, Strafford PW. Critical appraisal of health literature: prevalence or incidence of a health problem. Chronic Dis Can. 1998;19:170-6.

16. Schwarzer G. meta: Meta-Analysis with R. R package version 16-1. 2010.

17. Begg C, Mazumdar M. Operating characteristics of a rank correlation test for publication bias. Biometrics. 1994;50:1088-101.

18. Egger M, Smith G. Bias in meta-analysis detected by simple, graphical test. Br Med J. 1997;315:629-34.

19. Viechtbauer W. Conducting meta-analyses in $\mathrm{R}$ with the metafor package. J Stat Software. 2010;36:1-48.

20. Traumatic brain injury-Colorado, Missouri, Oklahoma, and Utah, 1990-1993. MMWR Morb Mortal Wkly Rep. 1997;46:8-11.

21 Incidence rates of hospitalization related to traumatic brain injury-12 states, 2002. Morb Mortal Wkly Rep. 2006;55:201-4.

22. Andersson EH, Bjorklund R, Emanuelson I, Stalhammar D. Epidemiology of traumatic brain injury: a population based study in western Sweden. Acta Neurol Scand. 2003;107:256-9.

23. Asemota AO, George BP, Bowman SM, Haider AH, Schneider EB. Causes and trends in traumatic brain injury for united states adolescents. J Neurotrauma. 2013;30:67-75.

24. Bazarian JJ, McClung J, Shah MN, Cheng YT, Flesher W, Kraus J. Mild traumatic brain injury in the United States, 1998-2000. Brain Inj. 2005;19:85-91.

25. Bowman SM, Bird TM, Aitken ME, Tilford JM. Trends in hospitalizations associated with pediatric traumatic brain injuries. Pediatrics. 2008;122:988-93.

26. Coronado VG, Thomas KE, Sattin RW, Johnson RL. The CDC traumatic brain injury surveillance system: characteristics of persons aged 65 years and older hospitalized with a TBI. J Head Trauma Rehabil. 2005;20:215-28.

27. Day H, Roesler J, Gaichas A, Kinde M. Epidemiology of emergency department-treated traumatic brain injury in Minnesota. Minn Med. 2006;89:40-4.
28. Fletcher AE, Khalid S, Mallonee S. The epidemiology of severe traumatic brain injury among persons 65 years of age and older in Oklahoma, 1992-2003. Brain Inj. 2007;21:691-9.

29. Gordon KE, Dooley JM, Wood EP. Descriptive epidemiology of concussion. Pediatr Neurol. 2006;34:376-8.

30. Guerrero JL, Thurman DJ, Sniezek JE. Emergency department visits associated with traumatic brain injury: United States, 1995-1996. Brain Inj. 2000;14:181-6.

31. Jager TE, Weiss HB, Coben JH, Pepe PE. Traumatic brain injuries evaluated in U.S. emergency departments, 1992-1994. Acad Emerg Med. 2000;7:134-40.

32. Koepsell TD, Rivara FP, Vavilala MS, Wang J, Temkin N, Jaffe KM, et al. Incidence and descriptive epidemiologic features of traumatic brain injury in King County, Washington. Pediatrics. 2011;128:946-54.

33. Leibson CL, Brown AW, Ransom JE, Diehl NN, Perkins PK, Mandrekar $\mathrm{J}$, et al. Incidence of traumatic brain injury across the full disease spectrum: A population-based medical record review study. Epidemiology. 2011;22:836-44.

34. Piatt JH Jr, Neff DA. Hospital care of childhood traumatic brain injury in the United States, 1997-2009: a neurosurgical perspective: clinical article. J Neurosurg Pediatr. 2012;10: 257-67.

35. Sosin DM, Sniezek JE, Thurman DJ. Incidence of mild and moderate brain injury in the United States, 1991. Brain Inj. 1996;10:47-54.

36. Thurman DJ, Alverson C, Dunn KA, Guerrero J, Sniezek JE. Traumatic brain injury in the United States: a public health perspective. J Head Trauma Rehabil. 1999;14:602-15.

37. Engberg Aa W, Teasdale TW. Traumatic brain injury in Denmark 1979-1996. A national study of incidence and mortality. Eur J Epidemiol. 2001;17:437-42.

38. Rates of hospitalization related to traumatic brain injury-nine states, 2003. MMWR Morb Mort Wkly Rep. 2007;56:167-70.

39. Alaranta H, Koskinen S, Leppanen L, Palomaki H. Nationwide epidemiology of hospitalized patients with first-time traumatic brain injury with special reference to prevention. Wien Med Wochenschr. 2000;150:444-8.

40. Andelic N, Sigurdardottir S, Brunborg C, Roe C. Incidence of hospital-treated traumatic brain injury in the Oslo population. Neuroepidemiology. 2008;30:120-8.

41. Arnarson EO, Halldorsson JG. Head trauma among children in Reykjavik. Acta Paediatr. 1995;84:96-9.

42. Baldo V, Marcolongo A, Floreani A, Majori S, Cristofolettil M, Dal Zotto A, et al. Epidemiological aspect of traumatic brain injury in Northeast Italy. Eur J Epidemiol. 2003;18:1059-63.

43. Bener A, Omar AO, Ahmad AE, Al-Mulla FH, Abdul Rahman YS. The pattern of traumatic brain injuries: a country undergoing rapid development. Brain Inj. 2010;24:74-80.

44. Bouillon B, Raum M, Fach H, Buchheister B, Lefering R, Menzel J, et al. The incidence and outcome of severe brain trauma - Design and first results of an epidemiological study in an urban area. Restor Neurol Neurosci. 1999;14:85-92.

45. Chiu WT, Huang SJ, Tsai SH, Lin JW, Tsai MD, Lin TJ, et al. The impact of time, legislation, and geography on the epidemiology of traumatic brain injury. J Clinl Neurosci. 2007;14:930-5.

46. Chiu WT, Hung CC, Shih CJ. Epidemiology of head injury in rural Taiwan - a four year survey. J Clin Neurosci. 1995;2:210-5.

47. Dahl E, von Wendt L, Emanuelson I. A prospective, populationbased, follow-up study of mild traumatic brain injury in children. Injury. 2006;37:402-9.

48. Diamond PT. Brain injury in the Commonwealth of Virginia: an analysis of Central Registry data, 1988-1993. Brain Inj. 1996;10:413-9.

49. Eisele JA, Kegler SR, Trent RB, Coronado VG. Nonfatal traumatic brain injury-related hospitalization in very young children-15 states, 1999. J Head Trauma Rehabil. 2006;21:537-43.

50. Emanuelson I, von Wendt L. Epidemiology of traumatic brain injury in children and adolescents in south-western Sweden. Acta Paediatr. 19971;86:730-5.

51. Gabella B, Hoffman RE, Marine WW, Stallones L. Urban and rural traumatic brain injuries in Colorado. Ann Epidemiol. 1997;7:207-12. 
52. Hawley CA, Ward AB, Long J, Owen DW, Magnay AR. Prevalence of traumatic brain injury amongst children admitted to hospital in one health district: a population-based study. Injury. 2003;34: 256-60.

53. Heskestad B, Baardsen R, Helseth E, Romner B, Waterloo K, Ingebrigtsen $\mathrm{T}$. Incidence of hospital referred head injuries in Norway: a population based survey from the Stavanger region. Scand J Trauma Resus Emerg Med. 2009;17:6.

54. Hillier SL, Hiller JE, Metzer J. Epidemiology of traumatic brain injury in South Australia. Brain Inj. 1997;11:649-59.

55. Ingebrigtsen $T$, Mortensen $K$, Romner $B$. The epidemiology of hospital-referred head injury in northern Norway. Neuroepidemiology. 1998; 17:139-46.

56. Kim H, McCarthy-Barnett K, Garneau D. Traumatic brain injury in Rhode Island. Med Health R I. 2009;92:109-10.

57. Kleiven S, Peloso PM, von Holst H. The epidemiology of head injuries in Sweden from 1987 to 2000. Inj Control Safety Promotion. 2003;10:173-80.

58. Koskinen S, Alaranta $\mathrm{H}$. Traumatic brain injury in Finland 1991-2005: a nationwide register study of hospitalized and fatal TBI. Brain Inj. 2008;22:205-14.

59. Langlois JA, Kegler SR, Butler JA, Gotsch KE, Johnson RL, Reichard AA, et al. Traumatic brain injury-related hospital discharges. Results from a 14-state surveillance system, 1997. MMWR Surveill Summ. 2003;52:1-20.

60. Langlois JA, Rutland-Brown W, Thomas KE. The incidence of traumatic brain injury among children in the United States: differences by race. The J Head Trauma Rehabil. 2005;20: 229-38.

61. MacKenzie EJ, Edelstein SL, Flynn JP. Hospitalized head-injured patients in Maryland: incidence and severity of injuries. Md Med J. 1989;38:725-32.

62. MacKenzie EJ, Edelstein SL, Flynn JP. Trends in hospitalized discharge rates for head injury in Maryland, 1979-86. Am J Public Health. 1990;80:217-9.

63. Maegele M, Engel D, Bouillon B, Lefering R, Fach H, Raum M, et al. Incidence and outcome of traumatic brain injury in an urban area in Western Europe over 10 years. Eur Surg Res. 2007;39:372-9.

64. Masson F, Thicoipe M, Aye P, Mokni T, Senjean P, Schmitt V, et al. Epidemiology of severe brain injuries: a prospective populationbased study. J Trauma. 2001;51:481-9.

65. McCarthy ML, Serpi T, Kufera JA, Demeter LA, Paidas C. Factors influencing admission among children with a traumatic brain injury. Acad Emerg Med. 2002;9:684-93.

66. McKinlay A, Grace RC, Horwood LJ, Fergusson DM, Ridder EM, MacFarlane MR. Prevalence of traumatic brain injury among children, adolescents and young adults: prospective evidence from a birth cohort. Brain Inj. 2008;22:175-81.

67. Murgio A, Fernandez Mila J, Manolio A, Maurel D, Ubeda C. Minor head injury at paediatric age in Argentina. J Neurosurg Sci. 1999; 43:15-24

68. Peloso PM, von Holst H, Borg J. Mild traumatic brain injuries presenting to Swedish hospitals in 1987-2000. J Rehabil Medicine. 2004(43 Suppl):22-7.

69. Polinder S, Meerding WJ, van Baar ME, Toet $\mathrm{H}$, Mulder S, van Beeck EF. Cost estimation of injury-related hospital admissions in 10 European countries. J Trauma. 2005;59:1283-91.

70. Reid SR, Roesler JS, Gaichas AM, Tsai AK. The epidemiology of pediatric traumatic brain injury in Minnesota. Arch Pediatr Adolesc Med. 2001;155:784-9.

71. Rickels E, von Wild K, Wenzlaff $P$. Head injury in Germany: a population-based prospective study on epidemiology, causes, treatment and outcome of all degrees of head-injury severity in two distinct areas. Brain Inj. 2010;241: 491-504.

72. Rutland-Brown W, Langlois JA, Thomas KE, Xi YL. Incidence of traumatic brain injury in the United States, 2003. J Head Trauma Rehabil. 2006;21:544-8.

73. Sallee D, Moore M, Johnson M. Traumatic brain injuries in Alaska, 1996-1998. Alaska Med. 2000;42:37-40.

74. Schneier AJ, Shields BJ, Hostetler SG, Xiang H, Smith GA. Incidence of pediatric traumatic brain injury and associated hospital resource utilization in the United States. Pediatrics. 2006;118:483-92.

75. Servadei F, Antonelli V, Betti L, Chieregato A, Fainardi E, Gardini E, et al. Regional brain injury epidemiology as the basis for planning brain injury treatment. The Romagna (Italy) experience. J Neurosurg Sci. 2002;46:111-9.

76. Sills MR, Libby AM, Orton HD. Prehospital and in-hospital mortality: a comparison of intentional and unintentional traumatic brain injuries in Colorado children. Arch Pediatr Adolesc Med. 2005;159:665-70.

77. Steudel WI, Cortbus F, Schwerdtfeger K. Epidemiology and prevention of fatal head injuries in Germany-trends and the impact of the reunification. Acta Neurochir. 2005;147:231-42.

78. Styrke J, Stalnacke BM, Sojka P, Bjornstig U. Traumatic brain injuries in a well-defined population: epidemiological aspects and severity. J Neurotrauma. 2007;24:1425-36.

79. Tate RL, McDonald S, Lulham JM. Incidence of hospital-treated traumatic brain injury in an Australian community. Aust N Z J Public Health. 1998;22:419-23.

80. Thurman DJ, Jeppson L, Burnett CL, Beaudoin DE, Rheinberger MM, Sniezek JE. Surveillance of traumatic brain injuries in Utah. West J Med. 1996;165:192-6.

81. Tieves KS, Yang H, Layde PM. The epidemiology of traumatic brain injury in Wisconsin, 2001. WMJ. 2005;104:22-5, 54.

82. Tiret L, Hausherr E, Thicoipe M, Garros B, Maurette P, Castel JP, et al. The epidemiology of head trauma in Aquitaine (France), 1986: a community-based study of hospital admissions and deaths. International J Epidemiol. 1990;19:133-40.

83. Vazquez-Barquero A, Vazquez-Barquero JL, Austin O, Pascual J, Gaite L, Herrera S. The epidemiology of head injury in Cantabria. Eur J Epidemiol. 1992;8:832-7.

84. Ventsel G, Kolk A, Talvik I, Vali M, Vaikmaa M, Talvik T. The incidence of childhood traumatic brain injury in Tartu and Tartu County in Estonia. Neuroepidemiology. 2008;30:20-4.

85. von Elm E, Osterwalder JJ, Graber C, Schoettker P, Stocker R, Zangger P, et al. Severe traumatic brain injury in Switzerland feasibility and first results of a cohort study. Swiss Med Wkly. 2008;138:327-34.

86. von Wild KR, Wenzlaff P. Quality management in traumatic brain injury (TBI) lessons from the prospective study in 6.800 patients after acute TBI in respect of neurorehabilitation. Acta Neurochir Suppl. 2005;93:15-25.

87. Willer B, Dumas J, Hutson A, Leddy J. A population based investigation of head injuries and symptoms of concussion of children and adolescents in schools. Inj Prevent. 2004;10: 144-8.

88. Zygun DA, Laupland KB, Hader WJ, Kortbeek JB, Findlay C, Doig CJ, et al. Severe traumatic brain injury in a large Canadian health region. Can J Neurol Sci. 2005;32:87-92.

89. Coronado VG, McGuire LC, Sarmiento K, Bell J, Lionbarger MR, Jones $\mathrm{CD}$, et al. Trends in traumatic brain injury in the U.S. and the public health response: 1995-2009 [Erratum appears in J Safety Res. 2014;48:117]. J Safety Res. 2012;43: 299-307.

90. Nell V, Brown DS. Epidemiology of traumatic brain injury in Johannesburg-II. Morbidity, mortality and etiology. Social Sci Med. 1991;33:289-96.

91. Di Maggio C. Emergency department visits for traumatic brain injury in a birth cohort of publicly insured children. Am J Epidemiol. 2011;173:S232.

92. Piatt JH, Jr., Neff DA. Hospital care of childhood traumatic brain injury in the United States, 1997-2009: a neurosurgical perspective. J Neurosurg Pediatr. 2012;10:257-67.

93. Mauritz W, Brazinova A, Majdan M, Leitgeb J. Epidemiology of traumatic brain injury in Austria. Wien Klin Wochenschr. 2014;126:42-52.

94. Numminen HJ. The incidence of traumatic brain injury in an adult population-how to classify mild cases? Eu J Neurol. 2011;18:460-4.

95. Feigin VL, Theadom A, Barker-Collo S, Starkey NJ, McPherson K, Kahan $M$, et al. Incidence of traumatic brain injury in New Zealand: a population-based study. Lancet Neurol. 2013;12:53-64. 
96. Perez K, Novoa AM, Santamarina-Rubio E, Narvaez Y, Arrufat V, Borrell C, et al. Incidence trends of traumatic spinal cord injury and traumatic brain injury in Spain, 2000-2009. Accid Anal Prevent. 2012;46:37-44.

97. Kerr ZY, Harmon KJ, Marshall SW, Proescholdbell SK, Waller AE. The epidemiology of traumatic brain injuries treated in emergency departments in North Carolina, 2010-2011. N C Med J. 2014;75:8-14.

98. Harrison JE, Berry JG, Jamieson LM. Head and traumatic brain injuries among Australian youth and young adults, July 2000June 2006. Brain Inj. 2012;26:996-1004.

99. Harvey LA, Close JCT. Traumatic brain injury in older adults: characteristics, causes and consequences. Injury. 2012;43: 1821-6.

100. Cameron KL, Marshall SW, Sturdivant RX, Lincoln AE. Trends in the incidence of physician-diagnosed mild traumatic brain injury among active duty U.S. military personnel between 1997 and 2007. J Neurotrauma. 2012;29:1313-21.

101. Andelic N, Anke A, Skandsen T, Sigurdardottir S, Sandhaug M, Ader $\mathrm{T}$, et al. Incidence of hospital-admitted severe traumatic brain injury and in-hospital fatality in Norway: A national cohort study. Neuroepidemiology. 2012;38:259-67. English.

102. Walder B, Haller G, Bottequin E, Schoettker P, Ravussin P, Brodmann $\mathrm{M}$, et al. Severe traumatic brain injury in a high income country: a population-based prospective cohort study. Intens Care Med. 2012;38:S14

103. Rusnak M. Traumatic brain injury: giving voice to a silent epidemic. Nat Rev Neurol. 2013;9:186-7.

104. Thompson HJ, McCormick WC, Kagan SH. Traumatic brain injury in older adults: epidemiology, outcomes, and future implications. J Am Geriatr Soc. 2006;54:1590-5.

105. Steinberg L. A social neuroscience perspective on adolescent risktaking. Dev Rev. 2008;28:78-106.

106. Tomei KL, Doe C, Prestigiacomo CJ, Gandhi CD. Comparative analysis of state-level concussion legislation and review of current practices in concussion. Neurosurg Focus. 2012;33:E11:1-9.
107. Ellenbogen RG, Berger MS, Batjer HH. The National Football League and concussion: leading a culture change in contact sports. World Neurosurg. 2010;74:560-5.

108. Maas AI, Stocchetti N, Bullock R. Moderate and severe traumatic brain injury in adults. Lancet Neurol. 2008;7:728-41.

109. Roozenbeek B, Maas AI, Menon DK. Changing patterns in the epidemiology of traumatic brain injury. Nat Rev Neurol. 2013;9:231-6.

110. Bazarian JJ, Veazie P, Mookerjee S, Lerner EB. Accuracy of mild traumatic brain injury case ascertainment using ICD-9 codes. Acad Emerg Med. 2006;13:31-8.

111. Carroll CP, Cochran JA, Guse CE, Wang MC. Are we underestimating the burden of traumatic brain injury? Surveillance of severe traumatic brain injury using Centers for Disease Control International Classification of Disease, ninth revision, clinical modification, traumatic brain injury codes. Neurosurgery. 2012;71:1064-70.

112. Peloso PM, Carroll LJ, Cassidy JD, Borg J, von Holst H, Holm L, et al. Critical evaluation of the existing guidelines on mild traumatic brain injury. J Rehabil Med. 2004(43 Suppl): 106-12.

113. Mild Traumatic Brain Injury Committee of the Head Injury Interdisciplinary Special Interest Group of the American Congress of Rehabilitation Medicine. Definition of mild traumatic brain injury. J Head Trauma Rehabil. 1993;8:86-7.

114. Carroll LJ, Cassidy JD, Holm L, Kraus J, Coronado VG, WHO Colloborating Centre Task Force on Mild Traumatic Brain Injury. Methodological issues and research recommendations for mild traumatic brain injury: the WHO Collaborating Centre Task Force on Mild Traumatic Brain Injury. J Rehabil Med. 2004(43 Suppl):113-25.

115. Menon DK, Schwab K, Wright DW, Maas AI; Demographics and Clinical Assessment Working Group of the International and Interagency Initiative toward Common Data Elements for Research on Traumatic Brain Injury and Psychological Health. Position statement: definition of traumatic brain injury. Arch Phys Med Rehabil. 2010;91:1637-40. 